\title{
Acetaminophen Induced Oxidative and Histopathological Alterations in Hepatic Tissue: Protective Effects of Alstonia Scholaris Leaf Extracts
}

\author{
Pawan Kumar Verma ${ }^{1 *}$, Rajinder Raina ${ }^{1}$, Mudasir Sultana' ${ }^{1}$ Maninder Singh ${ }^{2}$, Pawan Kumar ${ }^{3}$ \\ 'Division of Veterinary Pharmacology and Toxicology, Faculty of Veterinary Sciences and Animal Husbandry, R S Pura, Jammu, 181102, Jammu \& Kashmir, INDIA. \\ 2Division of Veterinary Public Health and Epidemiology, Faculty of Veterinary Sciences and Animal Husbandry, R S Pura, Jammu, 181102, Jammu \& Kashmir, INDIA. \\ ${ }^{3}$ Division of Pathology, Indian Veterinary Research Institute, Izatnagar, Bareilly, UP. 243122, INDIA.
}

\begin{abstract}
Introduction: Alstonia scholaris Linn. is the common ingredients of various herbal formulation. Objectives: Present study was aimed to evaluate the oxidative and histopathological alterations in acetaminophen (APAP) induced hepatotoxicity and protective mechanisms of different leaf extracts of A. scholaris. Methods: Forty two wistar rats were randomly divided into seven groups with six rats in each and subjected to different treatments. Alterations in total oxidant status (TOS), total antioxidant status (TAS), oxidative stress index (OSI), total thiols (TTH), catalase (CAT), superoxide dismutase (SOD), glutathione peroxidase (GPx), glutathione-s-transferase (GST), malondialdehyde (MDA) levels and histopathological alterations in hepatic tissue were analyzed to assess the extent of hepatic damage induced by APAP and the protection imparted against it by aqueous or ethanolic leaf extract of $A$. scholaris. Results: Single high oral dose of APAP administration increased $(p<0.05)$ hepatic levels of TOS, OSI and MDA and reduced TAS, TTH, SOD, CAT, GPx and GST activities indicating alteration in antioxidant system of hepatic tissue. The histopathological studies showed severe hepatic degeneration, vacuolization and granulation in cytoplasm, fragmentation of nuclei and membranes and infiltration of mononuclear
\end{abstract}

cells on APAP treatment. Pre and post-treatments of aqueous or ethanolic extract following APAP administration restored TTH, reduced MDA and TOS and increased TAS compared to APAP treatment alone. Conclusions: Observations of histopathological and antioxidant parameters indicates that restoration of TAS and TTH levels by leaf extracts may be the primary protective mechanism in APAP induced hepatotoxicity. Further treatments with ethanolic extract showed more hepatoprotective potential than the aqueous extract of $A$. scholaris.

Key words: Total antioxidant status, Total thiols, Acetaminophen, Alstonia scholaris, Super oxide dismutase, Malondialdehyde.

Corresponding author: Dr. Pawan Kumar Verma, Assistant Professor, Division of Veterinary Pharmacology and Toxicology, Faculty of Veterinary Sciences and Animal Husbandry, R S Pura Jammu, 181102, Jammu \& Kashmir (INDIA).

Phone No: 09419111332;

Email: drrpawankv@yahoo.co.in

DOI : 10.5530/pj.2016.4.12

\section{INTRODUCTION}

Hepatic tissue has evolved complex antioxidant strategies to minimize the noxious effects of partially reduced species or inappropriate reactive oxygen or nitrogen species (ROS/RNS) formed during biotransformation. ${ }^{1}$ Antioxidants within cells/cell membranes or extracellular medium can be up-regulated to maintain balance between total oxidant status (TOS) and total antioxidant status (TAS) during excessive free radicals formation in tissue. ${ }^{2,3}$ Excess production of radicals or reduced antioxidant defense of tissue leads to oxidative damage to important macromolecules like membrane proteins, lipids and nucleic acid by these radicals. Failure to defend against these conditions results to chronic health complications viz. cancer, cardiovascular and neurological disorders etc. ${ }^{3}$ Acetaminophen (APAP) is one of the most common and widely used antipyretic available over the counter (OTC) for the therapeutic applications in mammals. It produces dose-dependent hepatotoxicity that can lead to acute liver failure on overdosing. ${ }^{4}$ Studies have shown that reduced antioxidant status and total thiols (TTH) levels in hepatic tissue are primarily responsible for the APAP induced hepatotoxicity in mammals during overdosing. ${ }^{5}$

Plant products have been shown significant antioxidant potential both via direct scavenging of free radicals or indirectly by modulating antioxidant defense of mammals to onslaught the excessive radicals generated. Studies have revealed that administration of phytochemicals reduce the free radicals induced damage in hepatocytes during hepatotoxicity in mammals by either increasing scavenging capacity of hepatocytes or reducing production of radicals during drug induced cellular damage. ${ }^{6-8}$
Alstonia scholaris Linn. (Family Apocynaceae) has rich source of alkaloids (picrinine, schloaricine, alstonine and rhazimanine, etc), triterpenes (botulin, ursolic acid, etc), polyphenols, etc. which are primarily responsible for different pharmacological activities. ${ }^{9-11}$ Polyphenolic compounds present in the leaf extract of $A$. scholaris exhibit potent in-vitro total antioxidant capacity and reducing power and also shown scavenging of free radicals like hydroxyl, peroxy and superoxide radicals. ${ }^{12,13}$ These phytochemicals also have important role in stabilizing lipid peroxidation thus reduces cellular damage. Therefore, the present study was aimed to investigate the oxidative and histopathological alterations in liver induced by acetaminophen (APAP) toxicity in wistar rats and its protection by different leaf extracts of Alstonia scholaris Linn.

\section{MATERIALS AND METHODS}

Collection and preparation of extracts: The leaves of Alstonia scholaris Linn. were collected from University Campus, R S Pura, Jammu after proper identification by Taxonomist, Department of Botany, University of Jammu (AU-2874), INDIA. Sufficient fresh leaves were collected and air-dried in shade for 3-4 weeks. Air dried leaves were pre-crushed and later pulverized into fine powder using electric blender. Aqueous and ethanolic extracts were prepared according to standard method. ${ }^{14}$ The dried aqueous and ethanolic leaf extracts of $A$. scholaris were stored in air tight container. The extracts were reconstituted in $0.1 \%$ carboxy methyl cellulose (CMC) for oral gavage in wistar rats.

Induction of hepatotoxicity in experimental animals: Wistar rats of either sex (175-200 g) were procured from Indian Institute of Integrative 
Medicine, Jammu. Animals were provided standard pelleted ration and drinking water ad libitum under standard managemental conditions. The experimental protocol was dully approved by Institutional Animal Ethics Committee (IAEC) vide letter no FVSc/C-11/2456-68. Single high oral dose of APAP ( $3 \mathrm{~g} / \mathrm{kg}$, body weight in $0.1 \%, \mathrm{CMC}$ ) was used for the induction of hepatotoxicity in experimental animals. ${ }^{15}$ Forty two rats were randomly divided into 7 groups with 6 rats in each. The control (Group I) received only distilled water for 7 days, Group II received vehicle $(0.1 \%, \mathrm{CMC}) 1 \mathrm{ml}$ followed by a single oral dose $(3 \mathrm{~g} / \mathrm{kg}$, body weight) of APAP (Sigma-Aldrich, USA) on the $5^{\text {th }}$ day of the administration. Group III was fed with standard drug silymarin $(100 \mathrm{mg} / \mathrm{kg}$, body weight) (Sigma-Aldrich, USA) orally daily for 7 days and received APAP at same dose rate on $5^{\text {th }}$ day of administration. Group IV and V received aqueous or ethanolic extract (300 mg/kg, body weight) of $A$. scholaris orally daily for 7 days, respectively. Group VI and VII received aqueous and ethanolic extracts similar to group IV and V, respectively; in addition APAP was administered on the $5^{\text {th }}$ day. The dose of plant extract was determined on the basis of reported toxic dose and different pharmacological activities of the plant. ${ }^{9,11}$ After 7 days of treatment, animals were sacrificed and hepatic tissue $(1 \mathrm{gm})$ was collected in $10 \mathrm{ml}$ ice cold phosphate buffer solution $(0.5 \mathrm{M}, \mathrm{pH}-7.4)$ for determining stress parameters and formal saline (10\%) for histopathological studies. Tissue samples were homogenized using teflon coated homogenizer at $1000 \mathrm{rpm}$ for 5-7 min at refrigerated temperature and 10\% tissue homogenate was prepared for determining various antioxidant parameters.

Assaying of antioxidant parameters: Total antioxidant status (TAS) was determined spectrophotometrically by using 2 , 2' -azinobis (3-ethylbenzothiazoline 6-sulphonate) (ABTS) according to the method described. ${ }^{16}$ TAS values were expressed as $\mathrm{mM}$ of ascorbic acid equivalents. Similarly, TOS level was measured using a novel automated method ${ }^{17}$ and results expressed in terms of $\mu \mathrm{mol} \mathrm{H}_{2} \mathrm{O}_{2}$ Equiv/ L. The percent ratio of TOS to TAS levels was used for the determination of oxidative stress index (OSI) ${ }^{18}$ Total thiols (TTH) and malondialdehyde (MDA) levels in tissue homogenate was determined as per the method described by Motchnik and Shafiq-ur-Rehman, respectively. ${ }^{19,20}$ The other antioxidant parameters viz., catalase (CAT), superoxide dismutase (SOD), glutathione peroxidase (GPx) and glutathione-S-transferase (GST) were determined in hepatic tissue using standard method. ${ }^{21-24}$

Histopathological studies: The histopathological studies were carried out according to standard protocol. ${ }^{25}$ The formalin (10\%) fixed hepatic tissues were embedded in paraffin, sectioned and stained with hematoxylin and eosin ( $\mathrm{H} \& \mathrm{E}$ ) followed by examination under a light microscope for histopathological assessment.

Statistical analysis: The antioxidant parameters are presented in mean \pm standard error. The results were evaluated by analysis of variance (ANOVA) in completely randomized design (CRD) using the Duncan Multiple Range Test at $5 \%$ level of significance.

\section{RESULTS}

Single oral dose administration of APAP significantly $(\mathrm{p}<0.05)$ decreased the levels of TAS (51\%), TTH (46.7\%) and significantly increased levels of TOS (65.4\%), OSI (235\%) and MDA (136\%) as compared to control group. Treatments with silymarin following APAP treatment failed to normalize the levels of TAS ( $44.8 \%$ reduced) and OSI ( $91.6 \%$ increased) in hepatic tissue. Pre-and post administrations of aqueous leaf extract of A. scholaris were also unable to restore the levels of TAS, OSI and TTH in hepatic tissue of APAP treated rats; however, treatment with ethanolic leaf extract restored the levels of all these parameters in APAP induced hepatotoxic rats (Figure 1).

Figure 2 present the alterations in the activities of CAT, SOD, GPx and GST in liver tissue of different groups of animals treated with either aqueous or ethanolic leaf extract alone or in combination with APAP in rats. APAP treatment significantly $(\mathrm{p}<0.05)$ decreased the activities of CAT (40.6\%), SOD (22.5\%), GPx (37.7\%) and GST (32.8\%) as compared to control animals. Pre-and post treatments of aqueous leaf extract of A. scholaris were unable to restore the activities of CAT, SOD, GPx, and GST whereas silymarin restored these parameters except for SOD. The treatment with ethanolic extract following APAP treatment restored the activities of CAT and GPx, increased activities of GST (33.4\%) and decreased SOD (25.4\%) from the control.

Administration of APAP significantly $(\mathrm{p}<0.05)$ significantly increased the MDA levels (136\%) as compared to control group. Pre and post treatment with either aqueous or ethanolic extract significantly $(\mathrm{p}<0.05)$ reduced the level of MDA as compared to APAP alone exposed group but values were higher $(\mathrm{p}<0.05)$ than control (Figure 3 ).

A semi-qualitative scoring of architectural damage of liver in histopathological examination has been shown in Table 1. Liver section of control and plant extracts alone treated groups showed normal hepatocytes that were polygonal in shape with eosinophilic granular cytoplasm and vesicular basophilic nuclei (Figure 4a). Single dose administration of APAP revealed presence of small to large areas of degenerative changes in hepatic tissue characterized by cytoplasmic dissolution, fluid accumulation and fragmentation of nuclei and membranes. At certain places there were also sinusoidal dilatation and infiltration of mononuclear cells along with proliferation of tissue around bile duct (Figure $4 \mathrm{~b}$ ) compared to control group. Treatment of silymarin or leaf extracts (aqueous or ethanolic) of $A$. scholaris following APAP treatment revealed presence of few focal areas of mononuclear infiltration around blood vessels and sinusoidal dilation in hepatic tissue. Hepatocytes showed granular and mild degenerative changes at few foci in extract pretreated animals. These degenerative changes in hepatic tissue were less severe in ethanolic leaf extract treatments than the aqueous extract (Figure $5 \mathrm{a}$ and $5 \mathrm{~b}$ ).

\section{DISCUSSION}

Acetaminophen is a potent antipyretic and produces dose dependent hepatotoxicity by excessive production of ROS/free radicals during metabolism in hepatocytes. Metabolism of APAP by cytochrome oxidase enzymes in hepatocytes produce $\mathrm{N}$-acetyl-p-benzo-quinoneimine (NAPQI), a highly reactive intermediate, and other free radicals viz. superoxide anion radicals, hydrogen peroxide, and hydroxyl radicals. ${ }^{26,27}$ In our previous report showed significant alterations in plasma hepatic biomarkers and antioxidant status in single high dose APAP administration in experimental animals. ${ }^{28}$ Present study showed significant decrease in TAS and increased TOS on APAP administration in hepatic tissue. The increased TOS may be due to excessive release of free radicals (NAPQI and other intermediates) and reduction in TAS in hepatic tissue may be contributed to the free radicals induced hepatotoxicity on APAP administration. Excess free radicals formed within hepatocytes during overdosing of APAP can oxidize macromolecules such as DNA, proteins and lipids which may lead to cellular dysfunctions and death. ${ }^{5,29}$ Histopathological examination of hepatic tissue of APAP administered rats revealed characteristic cytoplasmic dissolution, fragmentation of nuclei/ membranes and infiltration of mononuclear cells. Studies have shown that excessive free radicals have been implicated in wide range of biological effects such as increased membrane fragility and decreased cellular deformation and fluidity. ${ }^{30,31}$ Further study showed that treatment with APAP increased OSI i.e. ratio between TOS and TAS indicating disturbance in antioxidant status which may contribute to hepatic degenerative changes. $^{32}$

Cellular antioxidant defense consists of non-enzymatic (thiols, antioxidants, etc) and enzymatic (CAT, SOD, GPx, GST) components, which contributes a crucial role in free radicals induced cellular damage. 
Table 1: Semi-qualitative severity scoring of architectural damage on histopathological examination of the liver in different treated group

\begin{tabular}{|c|c|c|c|c|c|}
\hline Groups & $\begin{array}{l}\text { Infiltration of } \\
\text { PMN cells }\end{array}$ & $\begin{array}{l}\text { Vacuolization } \\
\text { in cytoplasm of } \\
\text { hepatic tissue }\end{array}$ & $\begin{array}{l}\text { Fatty } \\
\text { degeneration in } \\
\text { hepatic tissue }\end{array}$ & $\begin{array}{l}\text { Congestion of } \\
\text { hepatic tissue }\end{array}$ & $\begin{array}{c}\text { Proliferation of } \\
\text { tissue around } \\
\text { bile duct }\end{array}$ \\
\hline I. Control & - & - & - & - & - \\
\hline II. APAP & ++++ & +++ & +++ & ++++ & +++ \\
\hline III. Silymarin + APAP & ++ & + & ++ & + & - \\
\hline IV. Aqueous ext. & + & + & + & - & - \\
\hline VI. Aqueous ext.+ APAP & +++ & +++ & + & - & - \\
\hline VII. Ethanolic ext.+ APAP & + & + & - & + & - \\
\hline $\begin{array}{l}\text { APAP - acetaminophen, PMN - polymorphic mononuclear cells, } \\
(-) \text { indicates normal, }(+) \text { indicates mild, }(++) \text { indicates moderate, } \\
(+++) \text { indicates severe, and }(++++) \text { indicates extremely severe. }\end{array}$ & & & & & \\
\hline
\end{tabular}

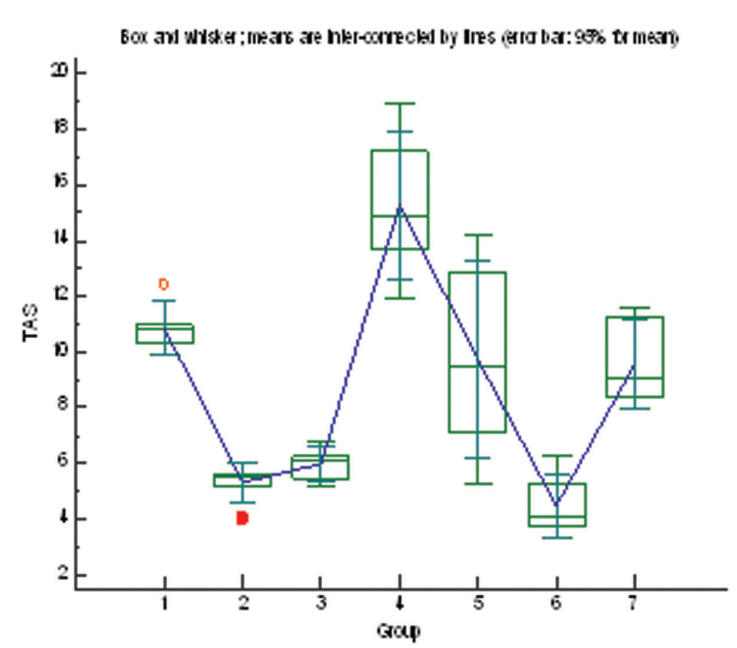

(a)

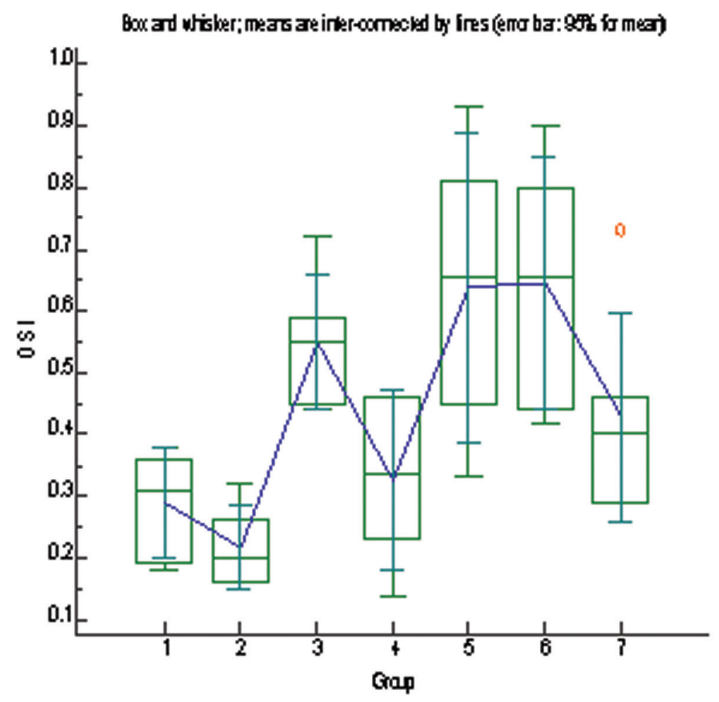

(c)

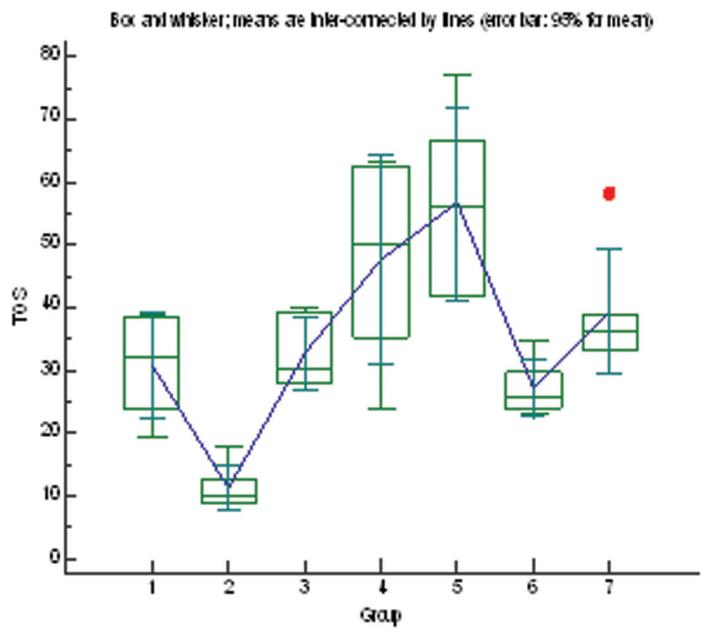

(b)

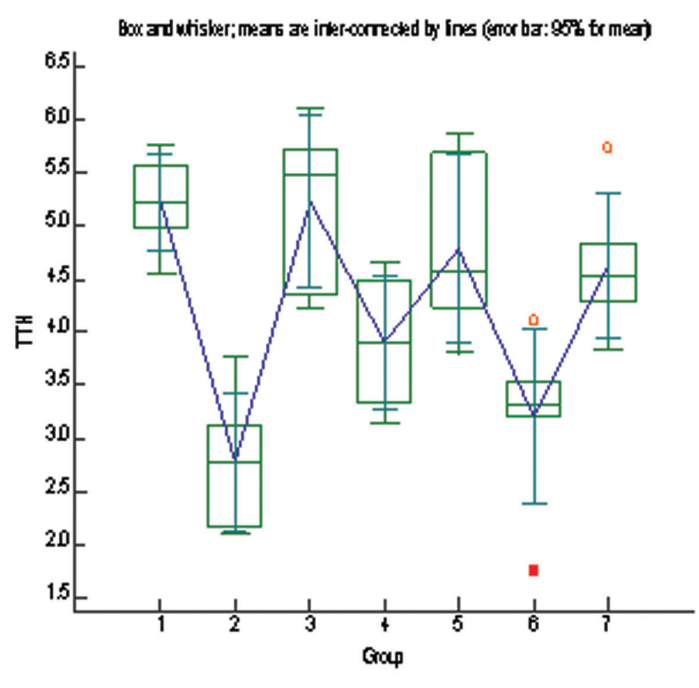

(d)

Figure 1: Effects of aqueous and ethanolic leaf extracts of $A$. scholaris treatments on antioxidant system viz. (a) total antioxidant status (TAS); (b) total oxidant status (TOS); (c) oxidative stress index (OSI) and (d) total thiols (TTH) levels in hepatic tissue of APAP induced hepatotoxic rats. (TAS, TTH expressed in mM and TOS in $\mu \mathrm{mol} \mathrm{H}_{2} \mathrm{O}_{2}$ Equiv. $\left.\mathrm{L}^{-1}\right)$. 


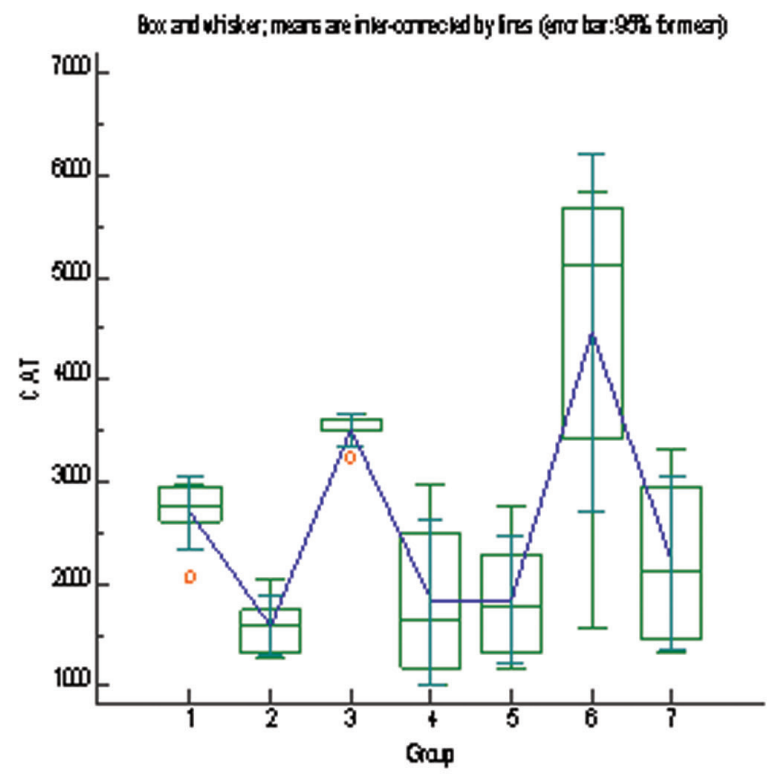

(a)

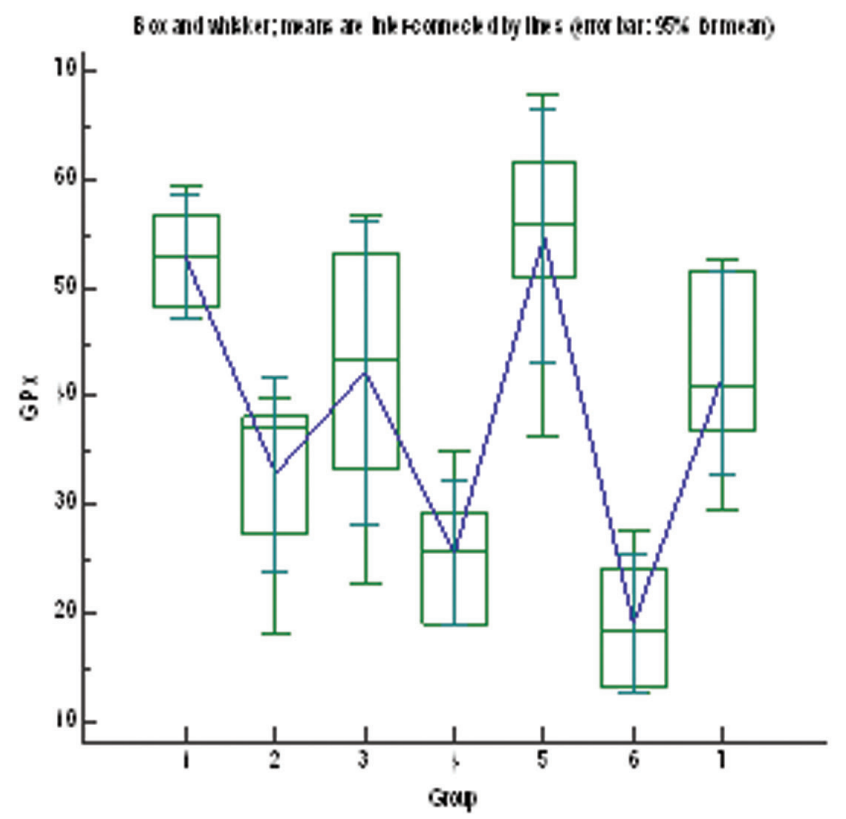

(c)

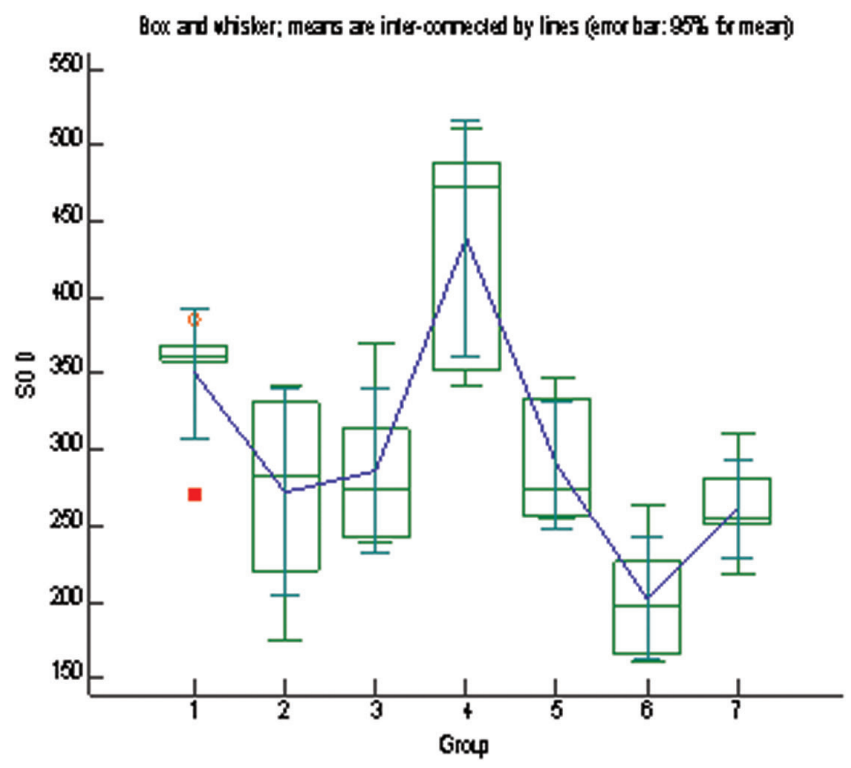

(b)

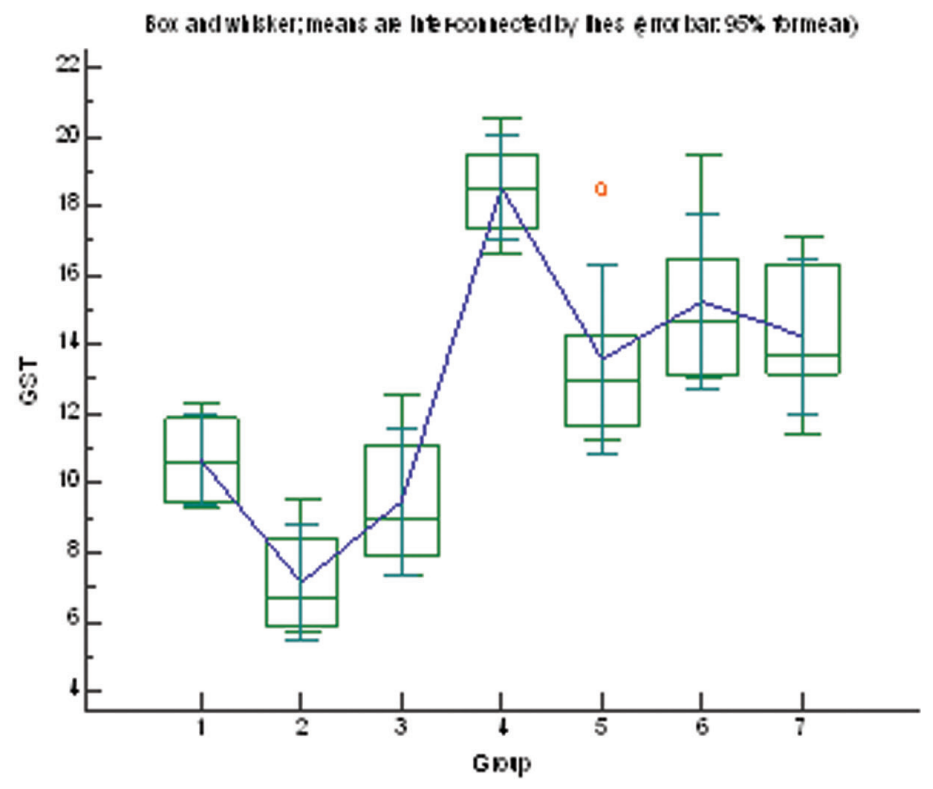

(d)

Figure 2: Effects of aqueous and ethanolic leaf extracts of $A$. scholaris treatments on activities of catalase (CAT), superoxide dismutase (SOD), glutathione peroxidase (GPx) and glutathione-s-transferase (GST) in hepatic tissue of APAP induced hepatotoxic rats. CAT ( $\mu \mathrm{mol} \mathrm{H}_{2} \mathrm{O}_{2}$ decomposed/ min/ $\mathrm{g}$ of tissue), SOD, GPx (Unit/ $\mathrm{g}$ of tissue), GST ( $\mu \mathrm{mol}$ of CDNB conjugate formed/ min/ $\mathrm{g}$ of tissue).

Reduction in levels of TTH and activities of antioxidant enzymes on APAP administration indicates reduction in level of TAS. Reduction in hepatic TTH level in present study indicate either increased utilization of thiols (-SH group) or decreased synthesis of thiols during APAP administration. ${ }^{26} \mathrm{CAT}$, SOD, GPx, GST are the primary antioxidant enzymes responsible for the scavenging peroxide, superoxide, hydroxy radicals produced in mammalian tissues during biochemical processes. ${ }^{3}$ Reduced antioxidant enzymes activities in hepatic tissue on APAP administration reduce the hepatic antioxidant defense leading to accumulation of these radicals in hepatocytes.

Increased production and reduced scavenging of free radicals generated in hepatic tissue following APAP administration leading to the free radicals induced damage to macromolecules and membrane lipid. These observations were further confirmed by determining the extent of lipid peroxidation i.e. malondialdehyde (MDA) level. MDA levels were significantly increased following APAP administration indicates increased 


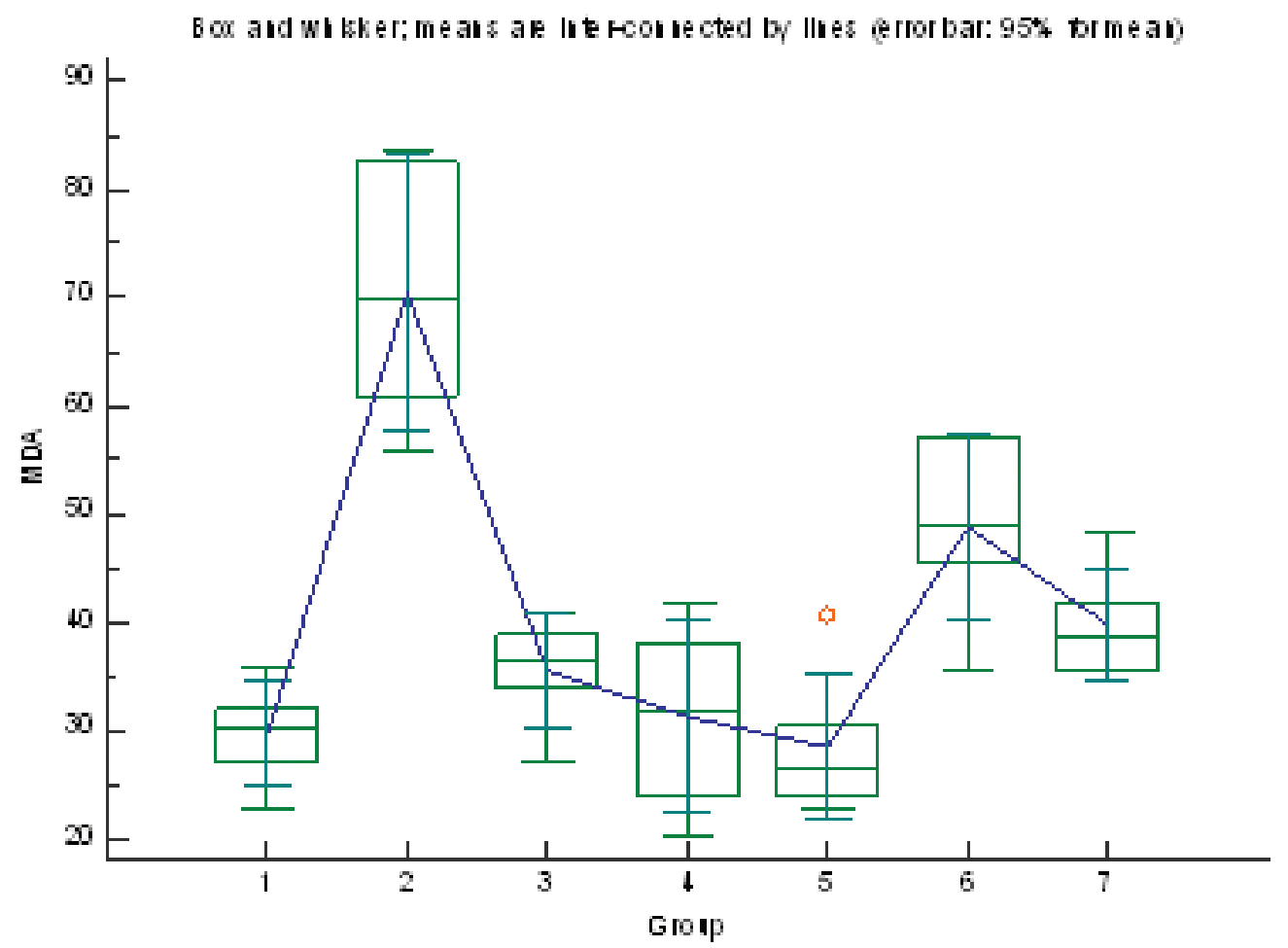

Figure 3: Effects of aqueous and ethanolic leaf extracts of $A$. scholaris treatments on malondialdehyde (MDA) level (nmoles MDA produced / g of tissue / hr) in hepatic tissue of APAP induced hepatotoxic rats.

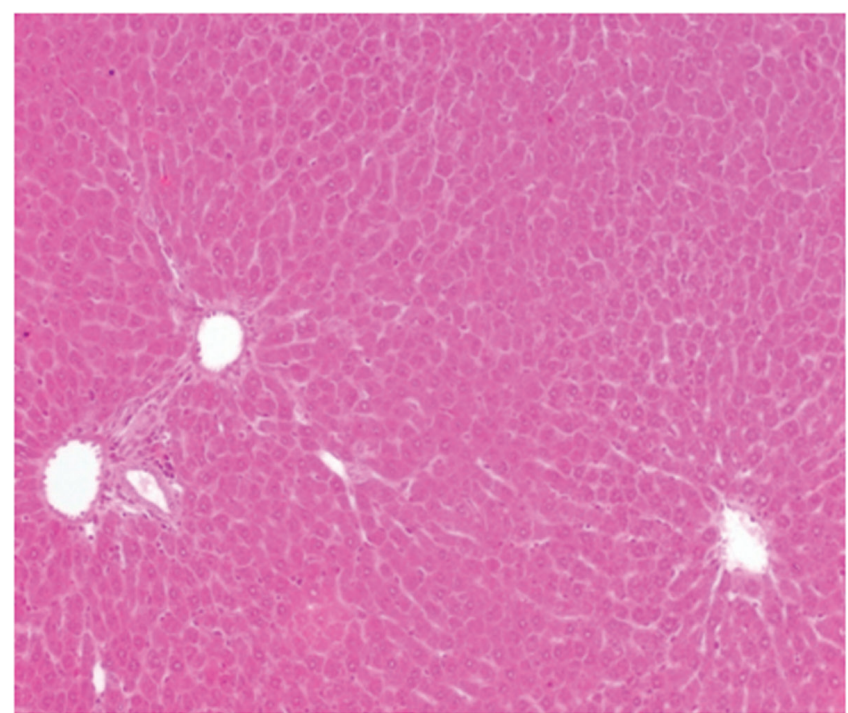

(a)

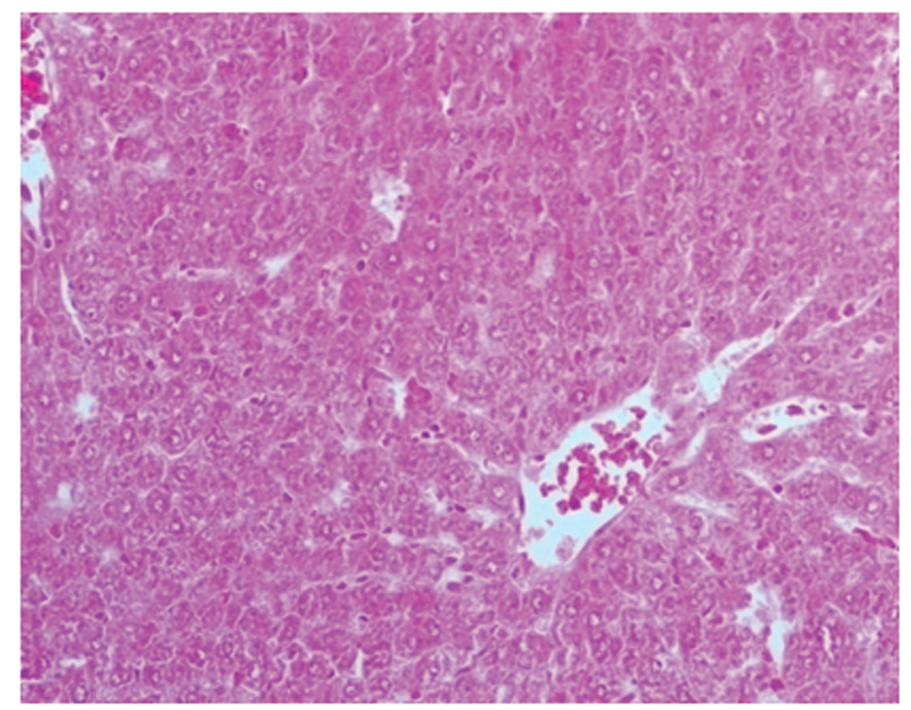

(b)

Figure 4: Liver section stained by hematoxylin and eosin showing intact histological structure of portal trait in liver (a) control rats (b) acetaminophen administered rats (x10).

membrane lipid peroxidation. Similarly, increased MDA level in hepatic tissue has also been reported following exposure of various hepatotoxicants in experimental studies. ${ }^{7,33}$

Leaf extracts of $A$. scholaris have high phenolic, flavonoid and carotene contents and exhibit potent in-vitro antioxidant functions by scavenging free radicals. ${ }^{12,13}$ Pre-and post treatments of ethanolic leaf extracts of
A. scholaris following APAP administration restored the TAS, TOS and TTH levels in hepatic tissue, whereas aqueous leaf extract treatment failed to restored these parameters. High hepatoprotective potential of ethanolic extract may be due to presence of high polyphenolic content in ethanolic leaf extract as compared to aqueous leaf extract of A. scholaris. ${ }^{12}$ Silymarin, a complex flavonoid, is a powerful antioxidant protects liver 


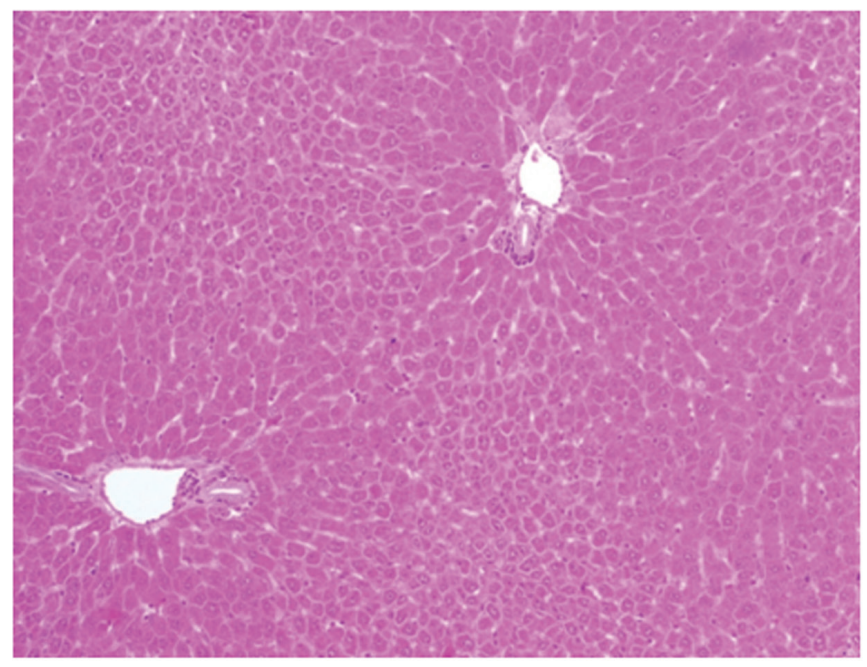

(a)

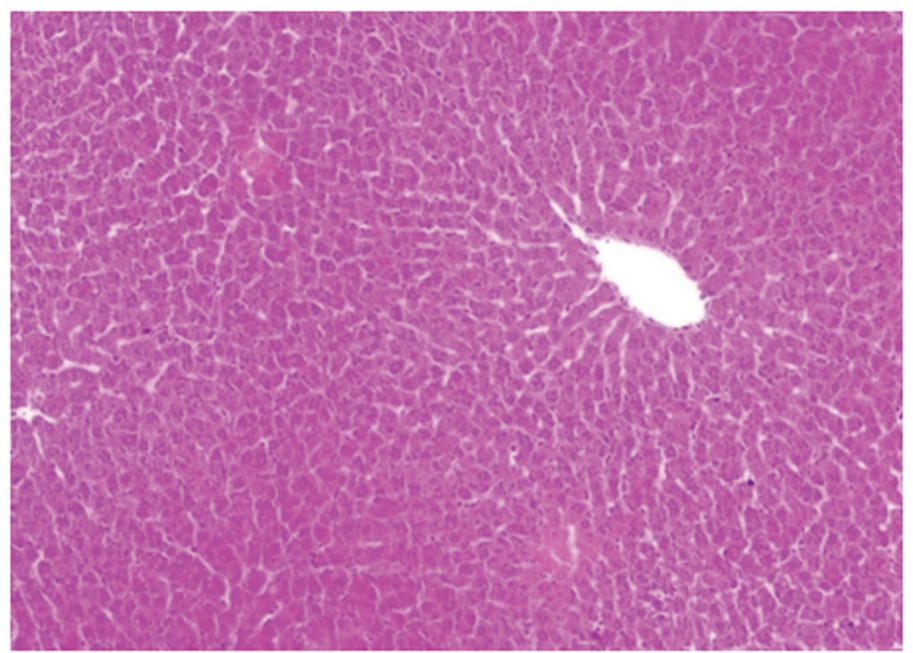

(b)

Figure 5: Histopathological alterations in hematoxylin and eosin stained liver section (a) pretreatments with silymarin following acetaminophen administration (b) pretreatment of ethanolic extract of $A$. scholaris following acetaminophen adminstration (x10).

cells by promoting protein synthesis and decrease the oxidation of reduced glutathione. ${ }^{34}$ Pretreatment with silymarin following APAP decreased TOS and increased TAS of hepatic tissue. Studies reported that silymarin helps in reducing lipid peroxidation by either by scavenging excess radicals produced or inhibit their production by $\mathrm{CYP}_{450}{ }^{34,35}$ Various studies have also shown that flavonoids present in the plant extract may increase glutamate cysteine ligase (GSL) activities which help in restoring the thiols level in hepatic tissue..$^{36,37}$

Treatment of aqueous or ethanolic leaf extract following APAP exposure reduced MDA level and reduction in MDA level was more pronounced in ethanolic extract than the aqueous leaf extract treated group. The reduction in MDA levels may be due to restoration of TAS, TTH and radicals scavenging enzymes by the phytochemicals compounds present in the ethanolic extract of $A$. scholaris. ${ }^{10,11,12,37}$ Less severe degenerative changes and infiltration of mononuclear cells in histopathological alterations in ethanolic leaf extract treated group indicates better hepatoprotective potential than the aqueous leaf extract of $A$. scholaris.

\section{CONCLUSION}

Oxidative and histopathological alterations in hepatic tissue indicates that single high dose of APAP, reduced TAS, TTH and antioxidant enzymes and increased TOS and OSI in hepatic tissue. Observations indicated that restoration of TAS and increased TTH levels by leaf extracts may be the primary hepatoprotective mechanisms in APAP induced hepatotoxicity. Further treatments with ethanolic extract showed more potential for restoring the functional and structural integrity of hepatocytes than the aqueous extract of A. scholaris of APAP induced hepatotoxicity in wistar rats.

\section{ACKNOWLEDGEMENTS}

Authors thank to the Dean, Faculty of Veterinary Sciences and Animal Husbandry, R S Pura, Jammu for providing necessary facilities for conducting the research activities of the division.

\section{CONFLICT OF INTEREST}

Authors declare there are no conflicts of interest.

\section{ABBREVIATION USED}

ABTS: 2, 2'-azinobis (3-ethylbenzothiazoline 6-sulphonate); APAP: Acetaminophen; NAPQI: N-acetyl-p-benzo-quinoneimine; TOS: Total oxidant status; TAS: Total antioxidant status; OSI: Oxidative stress index; TTH: Total thiols; CAT: Catalase; SOD: Superoxide dismutase, GPx: Glutathione peroxidase; GST: Glutathione-s-transferase; MDA: Malondialdehyde levels.

\section{REFERENCES}

1. Halliwell B, Gutteridge JM. The antioxidants of human extracellular fluids. Arch Biochem Biophys. 1990;280(1):1-8.

2. Ghiselli A, Serafini M, Natella F, Scaccini C. Total antioxidant capacity as a tool to assess redox status: critical view and experimental data. Free Radic Biol Med. 2000;29(11):1106-14.

3. Valko M, Leibfritz D, Moncol J, Cronin MT, Mazur M, Telser J. Free radicals and antioxidants in normal physiological functions and human disease. Int $J$ Biochem Cell Biol. 2007;39(1):44-84.

4. Lewerenz V, Hanelt S, Nastevska C, El-bahay C, Röhrdanz E, Kahl R. Antioxidants protect primary rat hepatocyte cultures against acetaminophen-induced DNA strand breaks but not against acetaminophen-induced cytotoxicity. Toxicology. 2003;191(2-3):179-87.

5. Nelson SD. Molecular mechanisms of the hepatotoxicity caused by acetaminophen. Semin Liver Dis. 1990;10(4):267-78

6. Rusu MA, Tamas M, Puica C, Roman I, Sabadas M. The hepatoprotective action of ten herbal extracts in CCl4 intoxicated liver. Phytother Res. 2005;19(9):744-9.

7. Verma PK, Sultana M, Raina R, Prawez S, Jamwal N. Hepatoprotective mechanisms of Ageratum conyzoides L. on oxidative damage induced by acetaminophen in wistar rats. Free Rad Antioxid. 2013;3(2):73-6.

8. Hasan S, Yusufoglu SGA, Abdel-Rahman RF. Antioxidant and antihyperglycemic effects of Ferula durdeana and Ferula huber-morathii in experimental diabetic rats. Int J Pharmacol. 2015;11(7):738-48.

9. Jagetia GC, Baliga MS. Evaluation of anticancer activity of the alkaloid fraction of Alstonia scholaris (Sapthaparna) in vitro and in vivo. Phytother Res. 2006; 20(2):103-9.

10. Shah AJ, Gowani SA, Zuberi AJ, Ghayur MN, Gilani AH. Antidiarrhoeal and spasmolytic activities of the methanolic crude extract of Alstonia scholaris L. are mediated through calcium channel blockade. Phytother Res. 2010;24(1): 28-32.

11. Subraya CK, Harikiran, Gupta D. Antioxidant and anti-inflammatory activity of Alstonia scholaris R.Br. stem bark extract. Free Rad. Antioxid. 2012;2(2):55-7.

12. Verma PK, Raina R, Sultana M, Prawez S, Singh M. Polyphenolic constituents and antioxidant/antiradical activity in different extracts of Alstonia scholaris (Linn.). Afr J Biotech. 2015;14(47):3190-7.

13. Minakshi, GC, Vasanth K, Tanupriya K. Phytochemical evaluation and antioxidant 
potential of Garcinia indica fruits on $\mathrm{H}_{2} \mathrm{O}_{2}$ induced oxidative stress in THP-1 Cell line. Int J Pharmacol. 2015;11(7):672-80.

14. Harborne JB. 1998. Phytochemical methods: A guide to modern techniques of plant analysis. Springer Science and Business Media.

15. Visen PK, Shukla B, Patnaik GK, Dhawan BN. Andrographolide protects rat hepatocytes against paracetamol-induced damage. J Ethnopharmacol. 1993;40(2):131-6.

16. Re R, Pellegrini N, Proteggente A, Pannala A, Yang M, Rice-evans C. Antioxidant activity applying an improved ABTS radical cation decolorization assay. Free Radic Biol Med. 1999;26(9-10):1231-7.

17. Erel O. A new automated colorimetric method for measuring total oxidant status. Clin Biochem. 2005;38(12):1103-11.

18. Aycicek A, Erel O, Kocyigit A, Selek S, Demirkol MR. Breast milk provides better antioxidant power than does formula. Nutrition. 2006;22(6):616-9.

19. Motchnik AP, Frei B, Ames NB. 1994. Measurement of antioxidants in human blood plasma, Protein thiols. In: Packer, L., (Eds.) Oxygen radicals in biological systems, Methods in Enzymology. California, Academic Press, 234(D) pp: 273-274

20. Shafiq-ur-rehman. Lead-induced regional lipid peroxidation in brain. Toxicol Lett. 1984;21(3):333-7.

21. Hafeman DG, Sunde RA, Hoekstra WG. Effect of dietary selenium on erythrocyte and liver glutathione peroxidase in the rat. J Nutr. 1974;104(5):580-7.

22. Marklund S, Marklund G. Involvement of the superoxide anion radical in the autoxidation of pyrogallol and a convenient assay for superoxide dismutase. Eur J Biochem. 1974;47(3):469-74

23. Habig WH, Pabst MJ, Jakoby WB. Glutathione S-transferases. The first enzymatic step in mercapturic acid formation. J Biol Chem. 1974;249(22):7130-9.

24. Aebi HE. Catalase. In: Bergmeyer, H.U. (Eds.) Methods of Enzymatic Analysis, New York, Academic Press, 1983. pp: 276-286

25. Drury AR, Wallington EA. Carleton's Histological Techniques $5^{\text {th }}$ Eds. Oxford University Press London, 1980
26. James LP, Mayeux PR, Hinson JA. Acetaminophen-induced hepatotoxicity Drug Metab Dispos. 2003;31(12):1499-506.

27. Mitchell JR, Jollow DJ, Potter WZ, Gillette JR, Brodie BB. Acetaminopheninduced hepatic necrosis. IV. Protective role of glutathione. J Pharmacol Exp Ther. 1973;187(1):211-7.

28. Verma PK, Raina R, Sultana M, Singh M. Modulatory effects of Alstonia scholaris on biochemical and antioxidant parameters in experimentally induced hepatotoxicity in wistar rats. Res J Med Plants. 2015;9(8):406-16.

29. Sallie R, Tredger JM, William R. Drug and liver biopharmaceutical. Drug Disposition. $1991 ; 12(4): 251-9$

30. Kaplowitz N, Tsukamoto H. Oxidative stress and liver disease. Prog Liver Dis 1996;14(2):131-59.

31. Hogg N. Free radicals in disease. Semin Reprod Endocrinol. 1998;16(4):241-88

32. Karadag-oncel E, Erel O, Ozsurekci Y. Plasma oxidative stress and total thio levels in Crimean-Congo hemorrhagic fever. Jpn J Infect Dis. 2014;67(1):22 6 .

33. Raina R, Baba NA, Verma PK, Sultana M, Singh M. Hepatotoxicity Induced by Subchronic Exposure of Fluoride and Chlorpyrifos in Wistar Rats: Mitigating Effect of Ascorbic Acid. Biol Trace Elem Res. 2015;166(2):157-62.

34. Zhang A, Sun $H$, Wang $X$. Recent advances in natural products from plants for treatment of liver diseases. Eur J Med Chem. 2013;63(5):570-7.

35. Ho PC, Saville DJ, Wanwimolruk S. Inhibition of human CYP3A4 activity by grapefruit flavonoids, furanocoumarins and related compounds. J Pharm Pharm Sci. 2001;4(3):217-27.

36. Myhrstad MC, Carlsen H, Nordström O, Blomhoff R, Moskaug JØ. Flavonoids increase the intracellular glutathione level by transactivation of the gammaglutamylcysteine synthetase catalytical subunit promoter. Free Radic Biol Med. 2002;32(5):386-93.

37. Johnson WM, Wilson-delfosse AL, Mieyal JJ. Dysregulation of glutathione homeostasis in neurodegenerative diseases. Nutrients. 2012;4(10):1399-440

\section{PICTORIAL ABSTRACT}

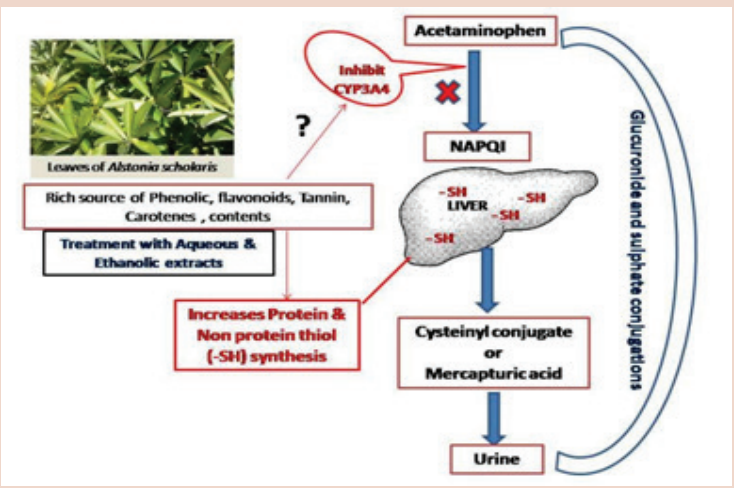

\section{SUMMARY}

- Significant alterations in histopathology of hepatic tissue and the levels of enzymatic, non-enzymatic components of antioxidant system on administration of APAP indicating acute hepatic damage.

- Treatments of aqueous or ethanolic extract following APAP administration restored TTH, reduced MDA and TOS and increased TAS compared to APAP treatment alone indicating protective effects.

- Further treatments with ethanolic extract showed more hepatoprotective potential than the aqueous extract of $A$. scholaris in APAP induced hepatotoxicity.

\section{ABOUT AUTHORS}

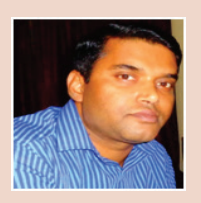

Pawan Kumar Verma: Is working as Assistant Professor (SS) in the Division of Veterinary Pharmacology \& Toxicology, SKUAST-Jammu since 2005. He obtained master degree from IVRI Izatnagar and PhD degree from SKUAST-Jammu. Dr Verma is working on bioprospection of herbs and engaged in preventive as well as therapeutic measure in acute and chronic disorders.

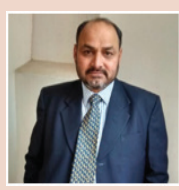

Rajinder Raina: Is Professor at Division of Veterinary Pharmacology \& Toxicology, SKUAST-Jammu. His research pursuit includes pharmacokinetics and safety of chemo-therapeutic agents in healthy and diseased animal models and elucidation of perturbations of metals and pesticides on antioxidant system of animals. Currently he is working on prospecting of plants for hepatoprotective, nephroprotective, antidiabetic and anticancer action. 